\title{
Accounting-Based Valuation With Changing Interest Rates
}

\author{
Dan Gode \\ Stern School of Business \\ New York University \\ Dgode@stern.nyu.edu \\ http://www.dangode.com
}

James Ohlson

Stern School of Business

New York University

Johlson@stern.nyu.edu

June 29, 2002

We acknowledge the helpful comments of an anonymous referee, Suresh Govindaraj, Stefan Reichelstein (editor), Merav Rom, Stephen Ryan, Ken Skogsvik, and seminar participants at the Chinese University of Hong Kong, National University of Singapore, Stanford University, Stern School, Stockholm School of Economics, and the Wharton School. 


\title{
Accounting-Based Valuation With Changing Interest Rates
}

\begin{abstract}
We generalize Ohlson's (1995) model to stochastic interest rates while making no specific assumptions about the stochastic process of interest rates. Our analysis of the case when earnings suffice for valuation yields three insights. (1) In the valuation function, the multiplier for forthcoming earnings depends on the current rate, but the multiplier for current earnings depends on the lagged rate. (2) In the residual earnings dynamic, the persistence of residual earnings increases in the current rate and decreases in the lagged rate. (3) In the earnings dynamic, the traditional random walk requires an additional term, current earnings multiplied by the percentage change in interest rates.
\end{abstract}

Keywords: Stochastic Interest Rates, Valuation, Ohlson Model, Random Walk Model of Earnings, Permanent Earnings

JEL Classification: M41, G12 


\section{Introduction}

Dynamic models relating accounting data to equity value need a discount factor to compute present values and price-earnings multiples. Ohlson (1995) assumes risk-neutrality and shows that the multiple for current earnings equals $R / r$ where $r$ is the risk-free rate and $R \equiv 1+r$. The model, however, assumes that the discount rate remains fixed over time. Relaxing this assumption is of obvious interest in a world of changing interest rates. ${ }^{1}$

This paper develops a class of valuation functions and derives the implied information dynamics when interest rates are stochastic. Like Ohlson (1995), two benchmark settings underpin this class: "mark-to-market accounting" or the "balance-sheet approach" where book value suffices for valuation, and, "earnings-sufficiency accounting" or the "income-statement approach" where earnings suffice for valuation. A weighted average of the two benchmarks combined with information besides current accounting data generalizes the model.

Three aspects of the model admit generality and versatility. First, the analysis assumes no particular stochastic process of interest rates. Second, realizations of accounting data and "other" information can depend on historical and expected interest rates. Third, unexpected changes in interest rates can correlate with unexpected earnings and growth in expected earnings.

While extending the mark-to-market model to stochastic rates is straightforward, extending the earnings-sufficiency model is not. Such an extension must confront the key issue of how one capitalizes earnings. Much of the analysis therefore pertains to the earnings-sufficiency model. The three main insights are as follows:

\footnotetext{
${ }^{1}$ Beaver (1999), p. 37, questions the assumption of constant discount rates in empirical studies. Feltham and Ohlson (1999) show how the residual income valuation can be extended to stochastic rates. They do not, however, consider closed-form valuation functions, PE multiples, and supporting information dynamics examined here.
} 
1. Valuation function (Propositions 1 and 2): Using Modigliani-Miller dividend policy irrelevancy, we show that if earnings $x_{t}$ for the period $(t-1, t)$ suffice for the cum-dividend value $\mathrm{P}_{\mathrm{t}}+\mathrm{d}_{\mathrm{t}}$, then $P_{t}+d_{t}=\left(R_{t-1} / r_{t-1}\right) x_{t}$ where $\mathrm{r}_{\mathrm{t}-1}$ is the spot interest rate at date $\mathrm{t}-1$ for the period $(t-1, t)$. The use of $r_{t-1}$ instead of $r_{t}$ in the multiplier rests on a simple yet powerful insight: The expected earnings rate for period $(t-1, t)$ is $r_{t-1}$, the rate at the beginning of the period, not $\mathrm{r}_{\mathrm{t}}$, the rate at the end of the period.

2. Residual earnings dynamic (Proposition 3): The persistence of residual earnings equals $r_{t} / r_{t-1}$, which oscillates around 1 rather than equal 1 as in Ohlson (1995).

3. Earnings dynamic (Corollary 1): The traditional random walk of earnings requires an additional term - the percentage change in interest rates multiplied by current earnings.

We then allow for stochastic interest rates in the Ohlson's (1995) weighted-average model with other information. Derivation of the implied information dynamic is straightforward (Proposition 4), but it brings out a new aspect of earnings forecasting. With stochastic rates, the relative importance of current earnings vis-à-vis book value in forecasting forthcoming earnings increases as the current rate decreases (Corollary 2).

Analysis of the more general model provides two testable hypotheses in addition to the modified random walk of earnings mentioned above:

1. Changes regression: In a returns-on-earnings regression, the coefficient of unexpected earnings (ERC) should be large when lagged interest rates are low (and conversely). ${ }^{2}$

\footnotetext{
${ }^{2}$ A comparative static analysis of Ohlson's (1995) model does not tell us whether the current rate or the lagged rate should affect ERC. There is also no guarantee that comparative statics will hold in dynamic settings. Our dynamic analysis formalizes and sharpens the empirical hypothesis.
} 
2. Levels regression: In a regression of price on book value, capitalized current earnings, and capitalized expected earnings, the first two coefficients decrease in the current rate while the third increases in the current rate. That is, as the current rate rises, the relative information content of current accounting data declines vis-à-vis expected earnings. (The lagged rate has no impact on the relative information content of the three variables.)

After introducing notation and core assumptions in section 2, the paper analyzes increasingly complex settings. Section 3 analyzes the mark-to-market model. Section 4 analyzes the earnings-sufficiency model. Section 5 analyzes the weighted average model with "other" information. Section 6 summarizes and concludes the paper.

\section{Notation and Basic Assumptions}

At date $t$, the "preceding" period refers to the period from date $t-1$ to date $t$, and the "forthcoming" period refers to the period from date $t$ to date $t+1$.

$\mathrm{x}_{\mathrm{t}}=\quad$ earnings for the period $\mathrm{t}-1$ to $\mathrm{t}$, i.e., the preceding period

$\mathrm{d}_{\mathrm{t}}=$ dividends, net of capital contributions, date $\mathrm{t}$

$\mathrm{P}_{\mathrm{t}}=$ ex-dividend market price of equity, date $\mathrm{t}$

$b_{t}=$ book value, date $t$

$g_{t}=P_{t}-b_{t}=$ goodwill, date $t$

$r_{t}=$ risk-free interest rate for the period $t$ to $t+1$. (At date $t, r_{t}$ is the current rate and $r_{t-1}$ is the lagged rate.)

$\mathrm{R}_{\mathrm{t}}=1+\mathrm{r}_{\mathrm{t}}$

$x_{t}^{a}=\mathrm{x}_{\mathrm{t}}-\mathrm{r}_{\mathrm{t}-1} \mathrm{~b}_{\mathrm{t}-1}=$ residual earnings for the preceding period 
Two assumptions will be maintained throughout the paper:

1. Risk neutrality and no arbitrage:

$\mathrm{P}_{\mathrm{t}}=\frac{E_{t}\left(\widetilde{P}_{t+1}+\widetilde{d}_{t+1}\right)}{R_{t}}$

(RNNA)

Note that $R_{t}$ is observed only at date $t$; it is random from the perspective of prior dates. ${ }^{3,4,5}$

2. Clean surplus relation:

$b_{t+1}=b_{t}+x_{t+1}-d_{t+1}$

(CSR)

The above assumptions imply the following goodwill equation that we use in our anlalysis:

$\mathrm{g}_{\mathrm{t}}=\frac{E_{t}\left(\tilde{g}_{t+1}+\tilde{x}_{t+1}^{a}\right)}{R_{t}}$

Subsequent sections introduce additional assumptions.

\section{The Mark-to-Market Model: The Balance-Sheet Approach}

We start with a simple but important benchmark -- the mark-to-market model. In this case, the balance sheet (i.e., the book value, $b_{t}$ ) provides sufficient value-relevant information. Since stochastic interest rates pose few problems in this setting, it provides a useful perspective before one considers more complicated settings. The three pertinent points are as follows:

1. Price depends only on book value and goodwill is zero. $P_{t}=b_{t}$.

\footnotetext{
${ }^{3}$ It is easy to construct an economy such that in equilibrium the expected return on an asset is the risk-free rate, and yet the rate changes stochastically over time. (The construction is particularly easy if one allows for unconstrained, event-contingent preferences.)

${ }^{4}$ For risk aversion, one can replace the expectation operator $\mathrm{E}$ by $\mathrm{E}^{*}$, which reflects risk-adjusted probabilities. [Huang and Litzenberger (1988)].

${ }^{5}$ Ohlson (1995), and others, assume constant interest rates and PVED $\left(P_{t}=\sum R^{-\tau} E_{\tau}\left[\widetilde{d}_{t+\tau}\right]\right)$. As is well known, PVED is equivalent to RNNA when rates are constant; thus RNNA does not deviate from prior research.
} 
2. Setting goodwill to zero in the goodwill equation (GE) yields $E_{t}\left[\tilde{x}_{t+1}^{a}\right]=0$ and $E_{t}\left[\tilde{x}_{t+1}\right]=r_{t} b_{t}=r_{t} P_{t}$, so that forthcoming expected earnings depend on the current rate.

3. Applying mark-to-market accounting does not require one to model the stochastic process of interest rates because prices already impound such information. For example, marking an investment fund to market simply requires setting the book value of each security to its market value. It does not require one to know the stochastic process of interest rates that the market is using to price the securities.

\section{The Earnings-Sufficiency Model: The Income-Statement Approach}

We now turn to the second benchmark: The income statement (i.e., earnings $\mathrm{x}_{\mathrm{t}}$ ) provides sufficient value-relevant information. ${ }^{6}$ As a point of reference, consider earnings sufficiency in a constant rate setting [Ohlson (1995) and Ryan (1988)]:

$P_{t}=\frac{R}{r} x_{t}-d_{t}$

where $\mathrm{R} / \mathrm{r}$ is the price-earnings multiple.

Given RNNA and constant interest rates, it follows that $P_{t}=E_{t}\left[\tilde{x}_{t+1}\right] / r$. Though earnings current or expected - and cum-dividend price both represent the same underlying information, one thinks of earnings as a "sufficient statistic" without specificity as to the accounting rules. ${ }^{7}$

The subsequent sections extend the valuation functions to allow for stochastic interest rates by specifying how the P-E multiples depend on interest rates.

\footnotetext{
${ }^{6}$ Section 4.2 illustrates the intuition and a practical application of the earnings-sufficiency accounting.

${ }^{7}$ Ohlson and Zhang (1998) construct accounting rules that map transactions into earnings sufficiency measurements.
} 


\subsection{The Valuation Function under Stochastic Discount Rates}

One may be tempted to extend the constant-rate setting to a stochastic-rate setting by simply replacing $\mathrm{r}$ by $\mathrm{r}_{\mathrm{t}}$ in the valuation function so that $P_{t}=\left(R_{t} / r_{t}\right) x_{t}-d_{t}$. The analysis below shows, however, that under any reasonable conditions, the multiple must be based on the lagged rate so that

$$
P_{t}=\frac{R_{t-1}}{r_{t-1}} x_{t}-d_{t} .
$$

Before deducing this relation, we consider a savings account to elucidate the intuition. In a savings account, the price $P_{t}$ is the account balance, $d_{t}$ is the withdrawal, earnings are the interest earned for the period $(\mathrm{t}-1, \mathrm{t})$, i.e., $x_{t}=r_{t-1} P_{t-1}$. Now RNNA implies $P_{t}=R_{t-1} P_{t-1}-d_{t}$. Substituting $P_{t-1}=x_{t} / r_{t-1}$, we get $P_{t}=\left(R_{t-1} / r_{t-1}\right) x_{t}-d_{t}$. The earnings rate for the period $(\mathrm{t}-1, \mathrm{t})$ is the rate prevailing at $t-1$, not $t$, so the multiple for earnings for the period $(t-1, t)$ depends on the rate at $\mathrm{t}-1$, not $\mathrm{t}$.

A savings account can be thought of as a special case of certainty. Uncertainty requires a more sophisticated analysis because under uncertainty $x_{t} \neq r_{t-1} P_{t-1}$ and $P_{t}+d_{t} \neq R_{t-1} P_{t-1}$. Therefore, we can no longer derive the valuation function by simply substituting $P_{t-1}=x_{t} / r_{t-1}$ in RNNA. We show below, however, that one can still derive $P_{t}=\left(R_{t-1} / r_{t-1}\right) x_{t}-d_{t}$ by using a Modigliani-Miller (MM) dividend policy irrelevancy precept.

We adapt an MM condition in Yee (2001) to allow for stochastic rates. Specifically, a firm's value at date $\mathrm{t}$ should be the same if the firm had lowered its dividends by $\$ \mathrm{z}$ at date $\mathrm{t}-1$, invested $\$ z$ in a zero NPV investment such as a Treasury bill, and raised date $t$ dividends by $R_{t-1} z$. The interest earned on the investment would have raised earnings for the period $(t-1, t)$ by $r_{t-1} z$. Yee's 
$\mathrm{MM}$ condition therefore corresponds to a requirement that $\mathrm{P}\left(\mathrm{x}_{\mathrm{t}}, \mathrm{d}_{\mathrm{t}}, \mathrm{r}_{\mathrm{t}}, \mathrm{r}_{\mathrm{t}-1}, \ldots\right)=\mathrm{P}\left(\mathrm{x}_{\mathrm{t}}+\mathrm{r}_{\mathrm{t}-1} \mathrm{z}, \mathrm{d}_{\mathrm{t}}+\mathrm{R}_{\mathrm{t}-1} \mathrm{Z}\right.$; $\left.\mathrm{r}_{\mathrm{t}}, \mathrm{r}_{\mathrm{t}-1}, \ldots\right)$ for any value of $z$. We next show that this MM condition implies that the multiplier equals $\mathrm{R}_{\mathrm{t}-1} / \mathrm{r}_{\mathrm{t}-1}$ as before.

Proposition 1: Assume that: (i) $\mathrm{P}_{\mathrm{t}}+\mathrm{d}_{\mathrm{t}}=\mathrm{f}\left(\mathrm{r}_{\mathrm{t}}, \mathrm{r}_{\mathrm{t}-1}, \ldots\right) \mathrm{x}_{\mathrm{t}}$ where $\mathrm{f}($.$) depends only on the history of$ interest rates ${ }^{8}$, and (ii) $\mathrm{P}_{\mathrm{t}}$ satisfies Modigliani-Miller condition as in $\mathrm{P}\left(\mathrm{x}_{\mathrm{t}}, \mathrm{d}_{\mathrm{t}} ; \mathrm{r}_{\mathrm{t}}, \mathrm{r}_{\mathrm{t}-1}, \ldots\right)=\mathrm{P}\left(\mathrm{x}_{\mathrm{t}}+\mathrm{r}_{\mathrm{t}-1} \mathrm{Z}\right.$, $\left.d_{t}+R_{t-1} z ; r_{t}, r_{t-1}, \ldots\right)$, where $z$ is any number. Then $f()=.R_{t-1} / r_{t-1}$.

Proof: See Appendix I.

Three aspects of proposition 1 are noteworthy. First, proposition 1 does not explicitly assume RNNA. The MM condition, however, implies that RNNA holds at the margin for a change in dividends.

Second, proposition 1 makes no assumptions about the stochastic process of interest rates. One can still derive the multiple because in the MM condition the earnings rate for the period ( $\mathrm{t}$ $1, t)$ is the $r_{t-1}$, not $r_{t}$. Had the earnings rate been $r_{t}$, which is not known at date $t-1$, one would have had to specify the stochastic process of interest rates to apply the MM condition at date t-1.

Third, the intuition behind the use of the lagged rate for capitalization extends to the capitalization of expected earnings as well. Proposition 1 and RNNA imply "capitalization consistency" in that expected earnings $\left(E_{t}\left[\tilde{x}_{t+1}\right]\right)$ are capitalized by the current rate $\left(\mathrm{r}_{t}\right)$ while current earnings $\left(\mathrm{x}_{\mathrm{t}}\right)$ are capitalized by the lagged rate $\left(\mathrm{r}_{\mathrm{t}-1}\right)$. RNNA implies $P_{t}=E_{t}\left[\tilde{P}_{t+1}+\tilde{d}_{t+1}\right] / R_{t}$. Substituting from proposition 1 , we get $P_{t}=E_{t}\left[\left(R_{t} / r_{t}\right) \tilde{x}_{t+1}\right] / R_{t}=E_{t}\left[\tilde{x}_{t+1}\right] / r_{t}$. Note that the last equality would not hold if the multiple for $\mathrm{x}_{\mathrm{t}}$ were $\left(R_{t+1} / r_{t+1}\right)$, since $\mathrm{r}_{\mathrm{t}+1}$ is not known at date $\mathrm{t}$.

\footnotetext{
${ }^{8}$ This representation allows the multiple $\mathrm{f}($.) to depend on expected interest rates as long as such expectations are based solely on the history of interest rates. Allowing the multiple to depend on accounting or non-accounting information other than interest rates is inconsistent with the notion that earnings suffice for valuation.
} 
In fact, as the next proposition shows, assuming a capitalization multiple for expected earnings provides an alternative way of deriving the multiple for current earnings.

Proposition 2: Assume (i) risk neutrality and no arbitrage (RNNA); (ii) $P_{t}=E_{t}\left[\tilde{x}_{t+1}\right] / r_{t}$; (iii) $\mathrm{P}_{\mathrm{t}}+\mathrm{d}_{\mathrm{t}}$

$=f\left(r_{t}, r_{t-1}, \ldots\right) x_{t}$ where $f($.$) depends only on the history of interest rates; and (iv) there are no$ particular restrictions on the stochastic process related to $r_{t}$ given $r_{t-1}, r_{t-2}, \ldots$. Then $f()=.R_{t-1} / r_{t-1}$.

Proof: In Appendix I.

Propositions 1 and 2 highlight two ways of expressing earnings sufficiency. One relates current price to current earnings $P_{t}=\left(R_{t-1} / r_{t-1}\right) x_{t}-d_{t}$, whereas the other relates current price to expected earnings, $P_{t}=E_{t}\left[\tilde{x}_{t+1}\right] / r_{t}$. Both relations use the rate at the beginning of the respective earnings measurement periods as the basis for earnings multiples.

We now describe a practical application of earnings sufficiency and show how it relates to the concept of smoothing.

\subsection{Understanding "Smoothing"--The Core Concept Underlying Earnings- Sufficiency}

Earnings sufficiency for valuation as defined above may appear abstract and contrived, especially in settings such as an investment fund, for which, at first glance, the mark-to-market model appears to be the only "correct" model. We now show that the earnings-sufficiency model yields valid and intuitive accounting measurements even for an investment fund. The implementation underscores the core concept of "smoothing" that underlies the earningssufficiency model. This concept is also used in practice to account for pension assets per GAAP. 
Let us compare the accounting alternatives for a simple investment fund that holds one share of the same equity security at all times. Without loss of generality, assume that dividends received by the fund are passed on to its investors. Then RNNA implies the following equation:

$P_{t}+d_{t}=R_{t-1} P_{t-1}+\tilde{\varepsilon}_{t}$

where $E_{t-1}\left[\tilde{\varepsilon}_{t}\right]=0$.

Mark-to-market accounting: One sets $b_{t}=P_{t}$. CSR yields $x_{t}=r_{t-1} P_{t-1}+\tilde{\varepsilon}_{t}$.

Earnings-sufficiency accounting: One sets $x_{t}=r_{t-1} P_{t-1}+\left(r_{t-1} / R_{t-1}\right) \tilde{\varepsilon}_{t}$. The book value is measured by applying CSR recursively with the initial condition of $b_{0}=0$. It is easy to verify that $P_{t+1}+d_{t+1}=\left(R_{t} / r_{t}\right) x_{t+1}$.

The difference between the two models is striking. In mark-to-market accounting, the entire value shock $\tilde{\varepsilon}_{t}$ is booked into earnings immediately. In contrast, in earnings-sufficiency accounting, only a part of the value shock $\tilde{\varepsilon}_{t}$ is booked into earnings in the current period.

GAAP accounting for pension assets approximates the smoothing inherent in the equation for measuring $\mathrm{x}_{\mathrm{t}}$. Pension assets are, of course, not marked to market. Instead, recognized earnings related to pension assets consist of two parts (i) expected earnings from plan assets, $r_{t-1} P_{t-1}$, and (ii) partial recognition of the difference between actual and expected return on plan assets, $\left(r_{t-1} / R_{t-1}\right) \tilde{\varepsilon}_{t}$

The definition of $x_{t}$ under earnings sufficiency highlights as to how such earnings generally depend on both current and lagged rates. $x_{t}$ depends on $r_{t-1}$ due to the component $r_{t-1} P_{t-1}$. But $x_{t}$ depends on $r_{t}$ as well as long as $\tilde{\varepsilon}_{t}$ correlates with realizations of $r_{t}$, which happens when $P_{t}$ 
depends on $r_{t}$. Because earnings, $x_{t}$, are always conceptualized as a flow variable pertaining to the period $(\mathrm{t}-1, \mathrm{t})$, the idea that $x_{t}$ relates to both of $r_{t}$ and $r_{t-1}$ has much appeal.

It remains to be seen whether the above earnings capitalization multiple can be incorporated into a full-fledged valuation framework in the spirit of Ohlson's (1995) model. Before developing this general model, we consider the implications of the earnings-sufficiency framework for the sustaining earnings dynamic.

\subsection{Residual Earnings Dynamic: Interest-rate Dependent Persistence}

Earnings sufficiency under constant interest rates results in residual earnings persistence being equal to one [Ohlson (1995)]. Specifically, residual earnings follow a strict random walk:

$\tilde{x}_{t+1}^{a}=x_{t}^{a}+\tilde{\varepsilon}_{t+1}$,

where $E_{t}\left[\tilde{\varepsilon}_{t+1}\right]=0$.

We generalize the equation to stochastic interest rates by hypothesizing the following information dynamic:

$\tilde{x}_{t+1}^{a}=\omega_{t} x_{t}^{a}+\tilde{\varepsilon}_{t+1}$,

where $\omega_{\mathrm{t}}$ can depend only on the history of interest rates.

It remains to be seen whether the above representation is valid when interest rates are stochastic and earnings sufficiency as previously defined applies. If it is a valid representation, then the two main questions are: Does $\omega_{\mathrm{t}}$ depend on the entire history of interest rates or is a smaller subset sufficient? Does $\omega_{\mathrm{t}}$ oscillate around 1 , its value with constant interest rates? 
Proposition 3: Given risk neutrality and no arbitrage (RNNA), and clean surplus (CSR), $P_{t}=\frac{R_{t-1}}{r_{t-1}} x_{t}-d_{t}$ implies $\omega_{t}=\frac{r_{t}}{r_{t-1}}$

Proof: In Appendix I.

Proposition 3 shows that one can generalize the Ohlson (1995) representation to stochastic interest rates in a parsimonious way. The residual earnings persistence parameter $\left(\omega_{t}\right)$ depends only on the lagged and current rate, not the entire history of interest rates. It decreases in the lagged rate and increases in the current rate. If the distribution of interest rates satisfies reasonable regularity conditions, then the median residual earnings persistence is 1 , which is its value with constant interest rates.

The intuition behind proposition 3 is as follows. As shown in the appendix, capitalized residual earnings equal goodwill.

$$
\begin{aligned}
& g_{t}=P_{t}-b_{t}=\frac{x_{t}^{a}}{r_{t-1}} \\
& E_{t}\left(\tilde{g}_{t+1}\right)=E_{t}\left(\frac{\tilde{x}_{t+1}^{a}}{r_{t}}\right)=\frac{E_{t}\left(\tilde{x}_{t+1}^{a}\right)}{r_{t}}
\end{aligned}
$$

Note that the last equality would not hold if the multiple were based on the current rate as the denominator of $\tilde{x}_{t+1}^{a}$ would be $\mathrm{r}_{\mathrm{t}+1}$, which is not known at date $\mathrm{t}$. The use of the lagged rate allows us to evaluate the expected goodwill without knowing the covariance between expected residual earnings and interest rates. Proposition 3, therefore, does not rely on a specific stochastic process of interest rates.

As shown in the appendix, RNNA implies that goodwill follows a random walk. Substituting for goodwill from the above equations, one gets: 
$\frac{\tilde{x}_{t+1}^{a}}{r_{t}}=\frac{x_{t}^{a}}{r_{t-1}}+\tilde{\varepsilon}_{t+1}$

Rearranging terms yields, $\omega_{t}=r_{t} / r_{t-1}$. In the special case of constant interest rates, the dynamic equation reduces to a random walk of residual earnings.

It is apparent that the converse of proposition 3 holds: $\omega_{t}=r_{t} / r_{t-1}$, RNNA, and CSR imply earnings sufficiency as defined. This observation shows that if one assumes $\omega_{t}=1$ along with RNNA and CSR, then earnings sufficiency cannot hold, i.e., a strict random walk (permanent earnings) and earnings sufficiency are mutually inconsistent when interest rates are stochastic. In fact, as Appendix II notes, $\omega_{t}=1$ implies that $\mathrm{P}_{\mathrm{t}}$ now also depends on $\mathrm{b}_{\mathrm{t}}$.

\subsection{Earnings Dynamic: A Modified Random Walk Reflecting Interest Rate Changes}

Ohlson (1995) implies the following stochastic process for earnings (rather than residual earnings):

$E_{t}\left[\tilde{x}_{t+1}\right]=x_{t}+r \Delta b_{t}$

The first term represents the standard random walk model of earnings, and it equals expected earnings in the absence of new net investment $\left(\Delta b_{t}\right)$ and constant interest rates. The second term represents the adjustment to expected earnings due to new investment. Because expected earnings depend on the current rate applied to new net investments, $r_{t}$ obviously replaces $r$ when interest rates are stochastic. The following corollary reveals that replacing $r$ by $r_{t}$ is not enough; stochastic interest rates introduce an additional term in the random walk model of expected earnings.

Corollary 1: $E_{t} x_{t+1}=x_{t}+r_{t} \Delta b_{t}+\% \Delta r_{t} x_{t}$ where $\% \Delta r_{t} \equiv\left(r_{t}-r_{t-1}\right) / r_{t-1}$ 
Proof: In Appendix I.

The third term, which prior research has not recognized, shows that the percentage change in interest rate, nor just the level of interest rates, affects earnings forecasts; an up tick in interest rates lead to higher earnings forecasts, and vice versa.

\section{A Weighted-Average of the Two Models with "Other" information}

The previous sections extend the mark-to-market and earnings-sufficiency benchmarks to stochastic interest rates. Ohlson (1995) also provides a more general model which is a weighted average of the two benchmarks and which also allows "other" value relevant information besides accounting data. There is an obvious motivation for examining a weighted-average model with "other" information. In the real world, both balance sheet and income statements are used for valuation and a model that incorporates both by taking their weighted average is appealing. "Other" information also has a crucial role. Without "other" information, the accounting data must pick up all value relevant information including expectations of future interest rates. For example, suppose the current rate drops and stock price rises because the market expects increase in future sales. If accounting statements were to suffice for valuation, current book value and earnings must reflect such higher expectations of future sales. This places a high burden on a transactions-based accounting system. Introducing "other" information allows us to pick up the effect of current rates on value while allowing the accounting data to be impacted gradually. ${ }^{9}$

We now extend this general model to stochastic rates and extract the following implications:

(i) The price can now depend on the current rate even if accounting data is held fixed $\left(\partial P_{t} / \partial_{r_{t}} \neq 0, \mathrm{x}_{\mathrm{t}}, \mathrm{b}_{\mathrm{t}}\right.$, and $\mathrm{d}_{\mathrm{t}}$ fixed). Previous sections ruled out this possibility by assuming that

\footnotetext{
${ }^{9}$ Nissim and Penman (1999) study empirically how interest rates influence subsequent accounting data.
} 
accounting data subsumed all value relevant information, including the current rate. (ii) In addition to the specification for price levels, we also derive one for returns as a function of unexpected earnings and unexpected "other" information. This specification leads to an empirically testable implication: The coefficient for unexpected earnings (ERC) increases in the lagged rate. (iii) We express the valuation function as a weighted average of three benchmark models: book value, capitalized earnings, and capitalized expected earnings. On the basis of this expression we state yet another empirical implication: An increase in interest rates reduces the information content of current accounting data relative to that of expected earnings.

\subsection{The Weighted Average Valuation Function with Other Information}

We first describe Ohlson's (1995) model with constant rates and then introduce stochastic rates. With fixed rates, Ohlson (1995) model specifies the valuation function as:

$P_{t}=k\left(\frac{R}{r} x_{t}-d_{t}\right)+(1-k) b_{t}+\beta v_{t} \quad$ where $k \in[0,1]$

and the supporting dynamics as

$$
\begin{aligned}
& \tilde{x}_{t+1}^{a}=\omega x_{t}^{a}+v_{t}+\tilde{\varepsilon}_{1, t+1} \\
& \tilde{v}_{t+1}=\quad \gamma v_{t}+\tilde{\varepsilon}_{2, t+1}
\end{aligned}
$$

where $E_{t}\left[\tilde{\varepsilon}_{j, t+\tau}\right]=0$ for all $\tau \geq 1$ and $\mathrm{j}=1,2$. The variable $v_{t}$ thus represents all "other" information influencing residual earnings forecasts and, to be consistent, the valuation function.

Given the RNNA condition, the parameters satisfy $\omega=\frac{k R}{k+r}$ and $\gamma=R-\frac{k+r}{r \beta}$. 
Allowing (a) $\omega$ and $\gamma$ to depend on interest rates while (b) keeping $\mathrm{k}$ and $\beta$ constant generalizes the model. We therefore consider the valuation function: ${ }^{10}$

$$
P_{t}=k\left(\frac{R_{t-1}}{r_{t-1}} x_{t}-d_{t}\right)+(1-k) b_{t}+\beta v_{t}
$$

The generalized model does not require a specification of the stochastic process of interest rates. This conclusion follows because $\mathrm{k}$ and $\beta$ are constants, and the multiple for current earnings is $R_{t-1} / r_{t-1}$, which ensures that one can evaluate $E_{t-1}\left[\widetilde{P}_{t}+\widetilde{d}_{t}\right]$ (the numerator of RNNA) without knowing the distribution of $r_{t}$ at date $t-1$. This model can be extended without specifying the stochastic process of interest rates as long as the "structure" of the valuation function at date $t$ is known at date $\mathrm{t}-1$. Appendix II details such a generalization in which $\mathrm{k}$ and $\beta$ depend on the lagged rate - i.e., $\mathrm{k}$ is replaced by $\mathrm{k}_{\mathrm{t}-1}$ and $\beta$ is replaced by $\beta_{\mathrm{t}-1}$ in the valuation function.

The information dynamics supporting the valuation function are as follows:

$$
\begin{array}{ll}
\tilde{x}_{t+1}^{a} & =\omega_{t} x_{t}^{a}+v_{t}+\tilde{\varepsilon}_{1, t+1} \\
\tilde{v}_{t+1} & =\quad \gamma_{t} v_{t}+\tilde{\varepsilon}_{2, t+1}
\end{array}
$$

where $E_{t}\left[\tilde{\varepsilon}_{j, t+\tau}\right]=0$ for all $\tau \geq 1$ and $\mathrm{j}=1,2$. It is assumed that the two persistence parameters $\omega_{\mathrm{t}}$ and $\gamma_{\mathrm{t}}$ depends at most on $\mathrm{k}, \beta$, and the history of interest rates.

\section{Proposition 4: Given RNNA and CSR,}

$$
P_{t}=k\left(\frac{R_{t-1}}{r_{t-1}} x_{t}-d_{t}\right)+(1-k) b_{t}+\beta_{v_{t}} \text { implies } \omega_{t}=\frac{r_{t}}{r_{t-1}} \frac{r_{t}+1}{r_{t}+k} k \text { and } \gamma_{t}=R_{t}-\frac{r_{t}+k}{r_{t} \beta} \text {. }
$$

Proof: In Appendix I. ${ }^{11}$

\footnotetext{
${ }^{10}$ Appendix I provides the motivation for this function using the Modigliani-Miller dividend policy irrelevancy conditions.
} 
The remaining subsections draw out the implications of the solution with no additional assumptions or modifications. We also discuss the critical role of other information, and state some empirical hypotheses that follow from the model.

\subsection{Residual Earnings Dynamic: Robustness of Ohlson (1995)}

This section draws out the implications of the functional form of $\omega_{t}$ and $\gamma_{t}$ derived in proposition 4. Like the earnings-sufficiency setting, $\omega_{\mathrm{t}}$ depends on the lagged as well as the current rate. In sharp contrast, $\gamma_{t}$ depends only on the current rate because $v_{t}$ represents generic "other" information, and there are no reasons why $\gamma_{t}$ should include a capitalization component based on the lagged rate.

On the basis of the earnings-sufficiency setting, one would expect $\omega_{t}$ to increase in $r_{t}$ and decrease in $r_{t-1}$. Differentiating $\omega_{t}$ with respect to $r_{t}$ and $r_{t-1}$ yields the anticipated conclusion: For $\mathrm{k}>0, \omega_{\mathrm{t}}$ increases in $\mathrm{r}_{\mathrm{t}}\left(\partial \omega_{t} / \partial r_{t}>0\right)$ and decreases in $\mathrm{r}_{\mathrm{t}-1}\left(\partial \omega_{t} / \partial r_{t-1}<0\right)$. Although the sensitivity of $\omega_{t}$ to interest rates may be expected, its functional form is not obvious. The first term $\left(\mathrm{r}_{\mathrm{t}} / \mathrm{r}_{\mathrm{t}-1}\right)$ reflects the "correction" due to the changing interest rates while the second term is the expression for $\omega$ when interest rates are not stochastic as in Ohlson (1995).

Differentiating $\omega_{\mathrm{t}}$ with respect to $\mathrm{k}$ yields $\partial \omega_{t} / \partial k>0$ for any $\mathrm{r}_{\mathrm{t}}, \mathrm{r}_{\mathrm{t}-1}>0$. That is, residual earnings are more persistent when earnings have more weight in the valuation function. We elaborate on this consistency between the relative importance of current earnings in forecasting and in valuation in the next section.

\footnotetext{
${ }^{11}$ If one assumes that $P_{t}=\alpha_{1}+\alpha_{2} \phi_{t-1} x_{t}+\alpha_{3} d_{t}+\alpha_{4} b_{t}+\alpha_{5} v_{t}$, then one can show that the dynamics imply the weighted-average valuation function.
} 


\subsection{Earnings Dynamic: Consistency between Valuation and Forecasting}

In Ohlson's (1995) model, residual earnings follow an auto-regressive process with persistence parameter $\omega$. One restates the residual earnings dynamic in terms of expected forthcoming earnings as follows:

$E_{t}\left[\tilde{x}_{t+1}\right]=\omega\left(x_{t}+r \Delta b_{t}\right)+(1-\omega) r b_{t}$

Three aspects of the expression are noteworthy. First, expected forthcoming earnings are a weighted average of the expected forthcoming earnings under the two benchmark models. Second, the residual earnings persistence parameter $(\omega)$ determines the weight assigned to the first component. Third, since $\omega$ increases in $\mathrm{k}$, the weights used in the earnings dynamics and the valuation function are mutually consistent. These three aspects generalize to the setting with stochastic interest rates except for the qualification that one cannot simply replace $\omega$ by $\omega_{\mathrm{t}}$.

Corollary 2: $E_{t}\left[\tilde{x}_{t+1}\right]=\theta_{t}\left(x_{t}+r_{t} \Delta b_{t}+\% \Delta r_{t} x_{t}\right)+\left(1-\theta_{t}\right) r_{t} b_{t}+v_{t}$ where $\theta_{t}=\frac{1+r_{t}}{k+r_{t}} k$.

Proof: In Appendix I.

The weight $\theta_{\mathrm{t}}$ has several interesting properties. First, $\theta_{t}=\left(r_{t-1} / r_{t}\right) \omega_{t}$, which equals $\omega_{\mathrm{t}}$ when rates are constant. Second, $\theta_{t}$ increases as $r_{t}$ decreases; i.e., the earnings-sufficiency component is relatively more important vis-à-vis mark-to-market component when current rate is low. In contrast, lagged rates do not affect $\theta_{\mathrm{t}}$. Third, $\theta_{\mathrm{t}}$ increases in k, i.e., as in Ohlson (1995), the weights used in the earnings dynamics and the valuation function are mutually consistent. 


\subsection{The Role of Other Information: Example of the Influence of Current Rates on Value}

We now provide an example that shows how current rates can affect value via other information $v_{\mathrm{t}}$. Suppose $\tilde{\varepsilon}_{2, t+1}=q\left(\tilde{r}_{t+1}-E_{t}\left[\tilde{r}_{t+1}\right]\right)+\tilde{u}_{t+1}$ where $E_{t}\left[\tilde{u}_{t+1}\right]=0$, and $\mathrm{q}$ is some fixed constant, which reflects the firm's type of business, accounting rules, etc. Hence, $\tilde{r}_{t+1}-E_{t}\left[\tilde{r}_{t+1}\right]$ defines the unanticipated change in interest rates, $E_{t}\left[\tilde{\varepsilon}_{2, t+1}\right]=0$ as required, and unexpected changes in interest rates correlate with the error term in the $v_{\mathrm{t}}$-dynamic. Recursive substitution then yields $v_{\mathrm{t}}$ as an explicit function or $\mathrm{r}_{\mathrm{t}}, \mathrm{r}_{\mathrm{t}-1}, E_{t-1}\left[\tilde{r}_{t}\right], E_{t-2}\left[\tilde{r}_{t-1}\right] \ldots$ and $u_{t}, u_{t-1}, \ldots$. This example underscores two important points. First, the variable $v_{t}$ can depend explicitly on the current rate, and, second, even though $v_{\mathrm{t}}$ depends on $\mathrm{r}_{\mathrm{t}}$, the evaluation of $E_{t}\left[\tilde{v}_{t+1}\right]$ is independent of the stochastic process that determines the distribution of $\tilde{r}_{t+1}$ given any date $t$ information.

A setting where $v_{t}$ depends on $r_{t}$ means that the accounting rules that produce $x_{t}$ and $b_{t}$ do not fully reflect the value implications of a change in interest rates for the period $(\mathrm{t}-1, \mathrm{t})$. Only with the passage of time will the accounting data reflect the prior history of interest rates. But this scenario also requires that the earnings forecasts depend on the current (and past) rates via $v_{t}$. In analytical terms, $E_{t}\left[\tilde{x}_{t+1}^{a}\right]$ depends on $v_{t}$, which in turn depends on the history of interest rates. Introducing $v_{t}$ thereby allows considerable generality as to how interest rates can influence value and earnings forecasts. 


\subsection{Two additional implications: A returns model and an expected earnings model}

Two additional implications of the above model generalize Ohlson (1995). First, one can explain the unexpected returns in terms of the surprise in residual earnings $\tilde{\varepsilon}_{1, t}$ and the surprise in other information $\tilde{\varepsilon}_{2, t}$. Specifically, as shown in Appendix I,

$\frac{\tilde{P}_{t}+\tilde{d}_{t}}{P_{t-1}}-R_{t-1}=\left(1+\alpha_{1, t-1}\right) \frac{\tilde{\varepsilon}_{1, t}}{P_{t-1}}+\alpha_{2, t-1} \frac{\tilde{\varepsilon}_{2, t}}{P_{t-1}}$

where $^{12}$

$\alpha_{1, t-1}=\frac{k}{r_{t-1}}$

$\alpha_{2, t-1}=\beta$.

The price-normalized response coefficient, $\alpha_{1, t-1}$ is known at the beginning of the return interval $(\mathrm{t}-1, \mathrm{t})$. One interprets $1+\alpha_{1, \mathrm{t}-1}$ as the response coefficient associated with unexpected earnings. An interesting empirical hypothesis follows: The response coefficient should be larger when interest rates are lower (for a fixed $\mathrm{k}, \alpha_{1, \mathrm{t}-1}$ increases as $\mathrm{r}_{\mathrm{t}-1}$ decreases).

Second, following Ohlson $(2001)^{13}$, one can substitute expected next-period earnings in lieu of $v_{t}$. As shown in the Appendix I,

$P_{t}=w_{1, t} b_{t}+w_{2, t}\left(\frac{R_{t-1}}{r_{t-1}} x_{t}-d_{t}\right)+w_{3, t} \frac{E_{t}\left[\tilde{x}_{t+1}\right]}{r_{t}}$

where $\sum_{j} w_{j, t}=1$

\footnotetext{
${ }^{12}$ Because of RNNA, the expected value of the left-hand side equals zero.

${ }^{13}$ For a discussion of the model see Hand (2001).
} 


$$
\begin{aligned}
& w_{1, t}=\left(1-k-\beta r_{t}+\beta \omega_{t} r_{t-1}\right)=(1-k)\left(1-\beta r_{t} \frac{r_{t}}{r_{t}+k}\right) \\
& w_{2, t}=\left(k-\beta \omega_{t} r_{t-1}\right)=k\left(1-\beta r_{t} \frac{r_{t}+1}{r_{t}+k}\right) \\
& w_{3, t}=\beta r_{t}
\end{aligned}
$$

Expressing value as a function of $\mathrm{b}_{\mathrm{t}}, \mathrm{x}_{\mathrm{t}}$, and $E_{t}\left[\tilde{x}_{t+1}\right]$ has an intuitive interpretation. Value derives from a weighted average of three benchmark models: (i) mark-to-market [ $\left.b_{t}\right]$, (ii) earnings-sufficiency $\left[\left(R_{t-1} / r_{t-1}\right) x_{t}-d_{t}\right]$, and (iii) capitalized expected earnings $\left[E_{t}\left[\tilde{x}_{t+1}\right] / r_{t}\right]$. Further note that components (ii) and (iii) reinforce the key idea of "capitalization consistency": The multiple for current earnings is based on the lagged rate, while the multiple for expected earnings depends on the current rate.

It is easy to verify that the weights associated with book value and capitalized earnings decrease as the interest rate rises while the weight associated with capitalized expected forthcoming earnings increases (with $\mathrm{k}>0, \partial w_{1, t} / \partial r_{t}<0$ and $\partial w_{2, t} / \partial r_{t}<0$ whereas $\partial w_{3, t} / \partial r_{t}>0$ ). A sharp empirical proposition thus follows: As interest rates rise, current accounting data has less information content as compared to expected earnings.

\section{Summary and Implications}

The paper provides a coherent framework for relating value to accounting data and "other information" when interest rates are stochastic. The paper starts with an examination of two benchmark models -- mark-to-market accounting where the balance sheet suffices for valuation 
and earnings-sufficiency accounting where the income statement suffices for valuation -- and then examines a weighted average of the two models with "other" information. ${ }^{14}$

Mark-to-market accounting poses few problems as the book value is set equal to the price, which impounds expectation of future interest rates. Therefore, much of the analysis revolves around the exact role of the current rate $r_{t}$ (the rate prevailing at the end of the earnings measurement period) versus the lagged rate $r_{t-1}$ (the rate prevailing at the beginning of the earnings measurement period) in an earnings-sufficiency setting. Our dynamic analysis clarifies the role of these rates in accounting-based valuation and forecasting, and provides insights that cannot be obtained from a comparative static analysis of Ohlson (1995).

The structure of the valuation function in earnings-sufficiency accounting hinges on the following crucial intuition: The earnings rate for a given period is the rate prevailing at the beginning of the earnings measurement period rather than the rate prevailing at the end of the earnings measurement period. This intuition and Modigliani-Miller dividend policy irrelevancy conditions imply the following "capitalization consistency" relation (propositions 1 and 2): the capitalization multiple for current earnings is based on the lagged rate $\left(1+1 / \mathrm{r}_{\mathrm{t}-1}\right)$ while the capitalization multiple for expected forthcoming earnings is based on the current rate $\left(1 / \mathrm{r}_{\mathrm{t}}\right)$.

Derivation of the residual earnings dynamic supporting earnings-sufficiency accounting shows that the residual earnings no longer follow a random walk. Their persistence is no longer 1; instead it now equals $r_{t} / r_{t-1}$ (proposition 3). The intuition is as follows: the standard riskneutrality-no-arbitrage condition and the clean surplus relation imply that the goodwill $\left(g_{t}=P_{t}-b_{t}=x_{t}^{a} / r_{t-1}=E_{t}\left(\tilde{x}_{t+1}^{a}\right) / r_{t}\right)$ must follow a random walk.

\footnotetext{
${ }^{14}$ It is unclear how stochastic interest rates will affect valuation under conservative accounting as examined in Feltham and Ohlson (1995) and Zhang (2000). Nor is it clear what the implications would be in case of non-
} 
Derivation of the related earnings dynamic shows that the traditional random walk of expected earnings now requires an additional term reflecting changes in interest rates. This term has not been recognized previously; it arises because the lagged rate is needed to scale current earnings while the current rate is needed to forecast forthcoming earnings. Thus, the percentage change in interest rate, nor just the level of interest rates, affects earnings forecasts; an up tick in interest rates lead to higher earnings forecasts, and vice versa.

Introducing "other" information poses few problems (proposition 4 and corollary 2) and makes the model more flexible as current accounting data is no longer required to fully reflect all value relevant information about interest rates. Instead, "other" information picks up value relevant information about expected future events that is not captured by the actual-transactionsbased accounting system. Allowing expected earnings to proxy for "other" information yields another important empirical prediction: an increase in interest rates reduces the information content of current accounting data relative to that of expected earnings.

A returns specification shows that unexpected return correlates with unexpected earnings and revisions in earnings expectations, consistent with traditional empirical specifications. However, a new empirical implication of the model is that the earnings-response coefficient depends on the lagged rate, not the current rate. Importantly, unexpected changes in interest rates will generally influence the returns specification because the model allows for "other" information to be correlated with current rates.

Overall, our analysis generalizes the Ohlson (1995) model to stochastic interest rates. Allowing the interest rates to be stochastic provides a better understanding of the key dynamic aspects accounting-based valuation framework that were obscured by the assumption of constant

linearities due to potential bankruptcies [Barth, Beaver, and Landsman (1998)]. 
interest rates in Ohlson (1995). Specifically, the lagged rate, not the current rate, seems to play the key role in relating prices to contemporaneous earnings, while the current rate plays a key role in earnings forecasting as well as in relating prices to expected earnings. Our analysis formalizes and sharpens earlier empirical hypotheses and also provides new empirical hypotheses regarding the relationship between prices and accounting variables. 


\section{Appendix I: Proofs}

\section{Proof of Proposition 1}

Suppose that the firm withholds $\$ z$ in dividends at date t-1. Since the one-period interest rate at time $\mathrm{t}-1$ is $\mathrm{r}_{\mathrm{t}-1}$, withholding $\$ \mathrm{z}$ at date $\mathrm{t}-1$ will increase earnings for the period $(\mathrm{t}-1, \mathrm{t})$ by $\mathrm{r}_{\mathrm{t}-1} \mathrm{z}$ and increase dividends at date $\mathrm{t}$ by $\left(1+\mathrm{r}_{\mathrm{t}-1}\right) \mathrm{z}$. Such withholding of dividends should have no impact on date $t$ value if dividend policy irrelevancy applies. That is,

$P_{t}=f(.) x_{t}-d_{t}=f().\left[x_{t}+r_{t-1} z\right]-\left[d_{t}+\left(1+r_{t-1}\right) z\right]$.

This implies $\mathrm{f}(.) \mathrm{r}_{\mathrm{t}-1} \mathrm{z}-\left(1+\mathrm{r}_{\mathrm{t}-1}\right) \mathrm{z}=0$ for all $\mathrm{z}$. Thus, $\mathrm{f}()=.\left(1+\mathrm{r}_{\mathrm{t}-1}\right) / \mathrm{r}_{\mathrm{t}-1}$.

Remark: The proof works only because $\mathrm{f}($.$) is assumed not to depend on earnings or$ dividends. However, if $\mathrm{f}($.$) were dependent on earnings, then \mathrm{P}_{\mathrm{t}}+\mathrm{d}_{\mathrm{t}}$ would be non-linear in $\mathrm{x}_{\mathrm{t}}$.

\section{Proof of Proposition 2}

Define $\mathrm{f}()=.\mathrm{f}\left(\mathrm{r}_{\mathrm{t}}, \mathrm{r}_{\mathrm{t}-1}, \ldots\right)$; RNNA combined with assumption (ii) implies:

$\mathrm{R}_{\mathrm{t}-1} \mathrm{P}_{\mathrm{t}-1}=\mathrm{E}_{\mathrm{t}-1}\left[\mathrm{P}_{\mathrm{t}}+\mathrm{d}_{\mathrm{t}}\right]=\mathrm{E}_{\mathrm{t}-1}\left[\mathrm{f}(.) \mathrm{x}_{\mathrm{t}}\right]$

Due to assumption (i), $\mathrm{R}_{\mathrm{t}-1} \mathrm{P}_{\mathrm{t}-1}=\mathrm{R}_{\mathrm{t}-1} \mathrm{E}_{\mathrm{t}-1}\left[\mathrm{x}_{\mathrm{t}}\right] / \mathrm{r}_{\mathrm{t}-1}$ so that $\left(\mathrm{R}_{\mathrm{t}-1} / \mathrm{r}_{\mathrm{t}-1}\right) \mathrm{E}_{\mathrm{t}-1}\left[\mathrm{x}_{\mathrm{t}}\right]=\mathrm{E}_{\mathrm{t}-1}\left[\mathrm{f}(.) \mathrm{x}_{\mathrm{t}}\right]$

This equation must be satisfied for all feasible stochastic processes of interest rates. In particular, consider the case when $r_{t}$ happens to be known at date $t-1$ for some history of interest rates. It then follows that

$\mathrm{E}_{\mathrm{t}-1}\left[\mathrm{f}(.) \mathrm{x}_{\mathrm{t}}\left[=\mathrm{f}(.) \mathrm{E}_{\mathrm{t}-1}\left[\mathrm{x}_{\mathrm{t}}\right]\right.\right.$, so that $\left(\mathrm{R}_{\mathrm{t}-1} / \mathrm{r}_{\mathrm{t}-1}\right) \mathrm{E}_{\mathrm{t}-1}\left[\mathrm{x}_{\mathrm{t}}\right]=\mathrm{f}(.) \mathrm{E}_{\mathrm{t}-1}\left[\mathrm{x}_{\mathrm{t}}\right]$.

Hence, $f()=.R_{t-1} / r_{t-1}$ as asserted.

\section{Proof of Proposition 3}

We can restate the expression for $\mathrm{P}_{\mathrm{t}}$ as: 
$P_{t}=b_{t}+\frac{x_{t}^{a}}{r_{t-1}}$

That is:

$g_{t}=\frac{x_{t}^{a}}{r_{t-1}}$

From the goodwill equation (GE) we get,

$\frac{R_{t} x_{t}^{a}}{r_{t-1}}=E_{t}\left(\frac{x_{t+1}^{a}}{r_{t}}+x_{t+1}^{a}\right)$

Since $r_{t}$ is known at date $t$, the above equation simplifies to

$E_{t} x_{t+1}^{a}=\frac{r_{t}}{r_{t-1}} x_{t}^{a}$. Thus, $\omega_{t}=\frac{r_{t}}{r_{t-1}}$ QED.

\section{Proof of Corollary 1}

From Proposition 3 we get, $E_{t} x_{t+1}^{a}=\frac{r_{t}}{r_{t-1}} x_{t}^{a}$. Substituting the expression for residual earnings, we get

$E_{t} x_{t+1}-r_{t} b_{t}=\frac{r_{t}}{r_{t-1}}\left(x_{t}-r_{t-1} b_{t-1}\right)$, which simplifies to

$E_{t} x_{t+1}=x_{t}+r_{t}\left(b_{t}-b_{t-1}\right)+\left(r_{t}-r_{t-1}\right) \frac{x_{t}}{r_{t-1}}$, or

$E_{t} x_{t+1}=x_{t}+r_{t} \Delta b_{t}+\% \Delta r_{t} x_{t}$

Modigliani-Miller restrictions on the weighted average valuation function

Let $P_{t}=\alpha_{1 t} x_{t}+\alpha_{2 t} d_{t}+(1-k) b_{t}+\beta v_{t}$

Dividend policy irrelevancy implies the following conditions: 
1. $\partial P_{t} / \partial d_{t}=-1$ and where $\partial x_{t} / \partial d_{t}=0, \partial b_{t} / \partial d_{t}=-1$, and $\partial v_{t} / \partial d_{t}=0$ [from Ohlson (1995)]

2. $\partial P_{t} / \partial d_{t-1}=-\left(1+r_{t-1}\right)$ and where $\partial x_{t} / \partial d_{t-1}=-r_{t-1}, \partial b_{t} / \partial d_{t-1}=-\left(1+r_{t-1}\right) \quad[$ from Yee (2001)], and $\partial v_{t} / \partial d_{t-1}=0 \quad$ [from Ohlson (1995)]

These two conditions yield the following:

$-\alpha_{2 t}-(1-k)=-1$

$-\alpha_{1 t} r_{t-1}-(1-k)\left(1+r_{t-1}\right)=-\left(1+r_{t-1}\right)$

Solving the above equation, we get the following:

$\alpha_{2 t}=-k$

$\alpha_{1 t}=\frac{k\left(1+r_{t-1}\right)}{r_{t-1}}$

\section{Proof of Proposition 4}

$g_{t}=P_{t}-b_{t}=k\left(\frac{R_{t-1}}{r_{t-1}} x_{t}-d_{t}-b_{t}\right)+\beta v_{t}$

Substituting for $b_{t}$ from the clean surplus relation, $b_{t}+d_{t}=x_{t}+b_{t-1}$, and using the definition of residual earnings we get:

$g_{t}=k \frac{x_{t}^{a}}{r_{t-1}}+\beta v_{t}$

Using the goodwill equation (GE) we get,

$R_{t} k \frac{x_{t}^{a}}{r_{t-1}}+R_{t} \beta v_{t}=E_{t}\left(k \frac{x_{t+1}^{a}}{r_{t}}+\beta v_{t+1}+x_{t+1}^{a}\right)$

Since $\mathrm{k}$ and $\beta$ are fixed and $v_{t+1}=\gamma_{t} \nu_{t}+\varepsilon_{2, t+1}$, we get

$E_{t} x_{t+1}^{a}=\frac{r_{t}+1}{r_{t}+k} r_{t} k \frac{x_{t}^{a}}{r_{t-1}}+\frac{r_{t}}{r_{t}+k} \beta\left(R_{t}-\gamma_{t}\right) v_{t}$ 
This implies,

$\omega_{t}=\frac{r_{t}}{r_{t-1}} \frac{r_{t}+1}{r_{t}+k} k$

and

$\frac{r_{t}}{r_{t}+k} \beta\left(R_{t}-\gamma_{t}\right)=1$

Thus,

$\gamma_{t}=R_{t}-\frac{r_{t}+k}{r_{t} \beta} \mathrm{QED}$

\section{Proof of Corollary 2}

From Proposition 4 we get, $E_{t} x_{t+1}^{a}=\frac{1+r_{t}}{r_{t}+k} r_{t} \frac{k}{r_{t-1}} x_{t}^{a}+v_{t}$. Substituting for residual earnings we

get, $E_{t} x_{t+1}=\frac{1+r_{t}}{r_{t}+k} r_{t} k \frac{\left(x_{t}-r_{t-1} b_{t-1}\right)}{r_{t-1}}+r_{t} b_{t}+v_{t}$

Define $\theta_{t}=\frac{1+r_{t}}{k+r_{t}} k$

Thus, $E_{t} x_{t+1}=\theta_{t}\left(\frac{r_{t}}{r_{t-1}}\left(x_{t}-r_{t-1} b_{t-1}\right)+r_{t} b_{t}\right)+\left(1-\theta_{t}\right) r_{t} b_{t}+v_{t}$, which can be restated as follows:

$E_{t} x_{t+1}=\theta_{t}\left(x_{t}+r_{t} \Delta b_{t}+\% \Delta r_{t} x_{t}\right)+\left(1-\theta_{t}\right) r_{t} b_{t}+v_{t}$ QED. 


\section{Derivation of the Coefficients in the Returns Specification}

$$
\begin{aligned}
& P_{t-1}=b_{t-1}+\frac{k}{r_{t-2}} x_{t-1}^{a}+\beta v_{t-1} \\
& P_{t}=b_{t}+\frac{k}{r_{t-1}} x_{t}^{a}+\beta v_{t} \\
& P_{t}+d_{t}=b_{t}+d_{t}+\frac{k}{r_{t-1}} x_{t}^{a}+\beta_{V_{t}}
\end{aligned}
$$

\section{From CSR}

$b_{t}+d_{t}=b_{t-1}+x_{t}$

$P_{t}+d_{t}=b_{t-1}+x_{t}+\frac{k}{r_{t-1}} x_{t}^{a}+\beta_{v_{t}}$

$=b_{t-1}+r_{t-1} b_{t-1}+x_{t}-r_{t-1} b_{t-1}+\frac{k}{r_{t-1}} x_{t}^{a}+\beta v_{t}$

$=R_{t-1} b_{t-1}+\frac{k+r_{t-1}}{r_{t-1}} x_{t}^{a}+\beta v_{t}$

$=R_{t-1} b_{t-1}+\frac{k+r_{t-1}}{r_{t-1}}\left(\omega_{t-1} x_{t-1}^{a}+v_{t-1}+\varepsilon_{1, t}\right)+\beta\left(\gamma_{t-1} v_{t-1}+\varepsilon_{2, t}\right)$

Substituting for $\omega_{\mathrm{t}-1}$ and $\gamma_{\mathrm{t}-1}$, we get,

$$
\begin{aligned}
& =R_{t-1} b_{t-1}+\frac{R_{t-1} k}{r_{t-2}} x_{t-1}^{a}+\left[\frac{k+r_{t-1}}{r_{t-1}}+\beta\left(R_{t-1}-\frac{k+r_{t-1}}{r_{t-1} \beta}\right) v_{t-1}+\left(\frac{k+r_{t-1}}{r_{t-1}}\right) \varepsilon_{1, t}+\beta \varepsilon_{2, t}\right. \\
& =R_{t-1} b_{t-1}+\frac{R_{t-1} k}{r_{t-2}} x_{t-1}^{a}+\beta R_{t-1} \nu_{t-1}+\frac{k+r_{t-1}}{r_{t-1}} \varepsilon_{1, t}+\beta \varepsilon_{2, t} \\
& =R_{t-1} P_{t-1}+\frac{k+r_{t-1}}{r_{t-1}} \varepsilon_{1, t}+\beta \varepsilon_{2, t}
\end{aligned}
$$

$$
\begin{aligned}
& \frac{P_{t}+d_{t}}{P_{t-1}}-R_{t-1}=\left(1+\alpha_{1, t-1}\right) \varepsilon_{1, t} / P_{t-1}+\alpha_{2, t-1} / P_{t-1} \\
& \alpha_{1, t-1}=\frac{k}{r_{t-1}} \\
& \alpha_{2, t-1}=\beta
\end{aligned}
$$




\section{Derivation of the Triple Weighted Average}

$$
P_{t}=(1-k) b_{t}+k\left(\frac{R_{t-1}}{r_{t-1}} x_{t}-d_{t}\right)+\beta v_{t}
$$

We can express $v_{t}$ in terms of expected earnings as follows:

$$
\begin{aligned}
& E_{t} x_{t+1}^{a}=\omega_{t} x_{t}^{a}+v_{t} \\
& v_{t}=E_{t} x_{t+1}^{a}-\omega_{t} x_{t}^{a} \\
& =E_{t} x_{t+1}-r_{t} b_{t}-\omega_{t}\left(x_{t}-r_{t-1} b_{t-1}\right) \\
& =E_{t} x_{t+1}-r_{t} b_{t}-\omega_{t}\left(x_{t}-r_{t-1}\left(b_{t}-x_{t}+d_{t}\right)\right) \\
& =E_{t} x_{t+1}-r_{t} b_{t}-\omega_{t}\left(R_{t-1} x_{t}-r_{t-1}\left(b_{t}+d_{t}\right)\right) \\
& =E_{t} x_{t+1}-r_{t} b_{t}-\omega_{t}\left(R_{t-1} x_{t}-r_{t-1}\left(b_{t}+d_{t}\right)\right)
\end{aligned}
$$

Substituting for $v_{\mathrm{t}}$ in the valuation function we get the following:

$$
\begin{aligned}
& P_{t}=(1-k) b_{t}+k\left(\frac{R_{t-1}}{r_{t-1}} x_{t}-d_{t}\right)+\beta\left(E_{t} x_{t+1}-r_{t} b_{t}-\omega_{t}\left[R_{t-1} x_{t}-r_{t-1}\left(b_{t}+d_{t}\right)\right]\right) \\
& =\left(1-k-\beta r_{t}+\beta \omega_{t} r_{t-1}\right) b_{t}+\left(k-\beta \omega_{t} r_{t-1}\right)\left(\frac{R_{t-1}}{r_{t-1}} x_{t}-d_{t}\right)+\beta r_{t} \frac{E_{t} x_{t+1}}{r_{t}}
\end{aligned}
$$

From Proposition 4, we know $\omega_{t}=\frac{r_{t}+1}{r_{t}+k} r_{t} \frac{k}{r_{t-1}}$. Thus, $\omega_{t} r_{t-1}=\frac{r_{t}+1}{r_{t}+k} r_{t} k$, which depends only on $r_{t}$.

Thus, we can express price as follows:

$$
\begin{aligned}
& P_{t}=w_{1, t} b_{t}+w_{2, t}\left(\frac{R_{t-1}}{r_{t-1}} x_{t}-d_{t}\right)+w_{3, t} \frac{E_{t} x_{t+1}}{r_{t}} \\
& \sum_{j} w_{j, t}=1 \\
& w_{1, t}=\left(1-k-\beta r_{t}+\beta \omega_{t} r_{t-1}\right) \\
& w_{2, t}=\left(k-\beta \omega_{t} r_{t-1}\right) \\
& w_{3, t}=\beta r_{t}
\end{aligned}
$$




\section{Appendix II: The Weighted Average Model with Variable but Known Weights}

We now examine a setting where the weights can vary over time, but are known at the beginning of a period. For brevity, we consider the setting without "other" information. The concepts illustrated in this appendix will remain unchanged if we introduce "other" information. Thus, price is expressed as follows:

$$
P_{t}=k_{t-1}\left(\frac{R_{t-1}}{r_{t-1}} x_{t}-d_{t}\right)+\left(1-k_{t-1}\right) b_{t}
$$

Rearranging the terms in the above equation and applying CSR, it follows that:

$$
R_{t} k_{t-1} \frac{x_{t}^{a}}{r_{t-1}}=E_{t}\left(k_{t} \frac{x_{t+1}^{a}}{r_{t}}+x_{t+1}^{a}\right)
$$

Inserting the last equation into the goodwill equation (GE) yields,

$$
R_{t} k_{t-1} \frac{x_{t}^{a}}{r_{t-1}}=E_{t}\left(k_{t} \frac{x_{t+1}^{a}}{r_{t}}+x_{t+1}^{a}\right)
$$

Since $\mathrm{k}_{\mathrm{t}}$ and $\mathrm{r}_{\mathrm{t}}$ are known at time $\mathrm{t}$, the RHS equals $\frac{k_{t}}{r_{t}} E_{t} x_{t+1}^{a}+E_{t} x_{t+1}^{a}$ and one obtains the following: ${ }^{15}$

$$
E_{t} x_{t+1}^{a}=\frac{r_{t}+1}{r_{t}+k_{t}} r_{t} \frac{k_{t-1}}{r_{t-1}} x_{t}^{a}
$$

The residual earnings persistence parameter therefore is represented by

\footnotetext{
${ }^{15}$ If $\mathrm{k}_{\mathrm{t}}$, instead of $\mathrm{k}_{\mathrm{t}-1}$, is the weight in the pricing equation, i.e., the weight is determined at the end of the period rather than at the beginning, then we would need to know the covariance of $\mathrm{k}_{\mathrm{t}+1}$ and $\frac{x_{t+1}^{a}}{r_{t}}$.
} 
$\omega_{t}=\frac{r_{t}+1}{r_{t}+k_{t}} r_{t} \frac{k_{t-1}}{r_{t-1}}$

In this expression, one can think of $\omega_{\mathrm{t}}$ as being the endogenous result of realization of interest rates and $\mathrm{k}_{\mathrm{t}}$ 's where the $\mathrm{k}_{\mathrm{t}}$ 's follow some exogenous stochastic process (though, as noted, the weights are determined at the beginning of a period). More important, as shown below, we can rearrange the terms to state $k_{t}$ in terms $\omega_{t}, k_{t-1}, r_{t}$, and $r_{t-1}$, i.e., we can think of $\omega_{t}$ as being exogenous.

$k_{t}=\frac{r_{t}}{\omega_{t}} R_{t} \frac{k_{t-1}}{r_{t-1}}-r_{t}$

If one substitutes recursively, it follows that $\mathrm{k}_{\mathrm{t}}$ is some function of the history of interest rates and the history of $\omega_{t}$; i.e., one can write $\mathrm{k}_{\mathrm{t}+1}=\mathrm{f}\left(\mathrm{r}_{\mathrm{t}}, \mathrm{r}_{\mathrm{t}-1}, \ldots, \omega_{\mathrm{t}}, \omega_{\mathrm{t}-1}, \ldots\right)$ where the $\omega_{\mathrm{t}}$ are determined by some exogenous process.

One can now ask the following question: What happens if $\omega_{\mathrm{t}}$ is simply a constant, such as $\omega_{\mathrm{t}}$ $=1$ ? That is, what happens if residual earnings follow a random walk and interest rates can change over time? The answer is clear: $\mathrm{P}_{\mathrm{t}}$ will generally depend on book value as well as capitalized earnings (adjusted for dividends). This is because, in contrast to the setting in which $r_{t}$ is constant, $\mathrm{k}_{\mathrm{t}}$ need not be 1 when $\omega_{\mathrm{t}}=1$, i.e., the weight on book value $\left(1-\mathrm{k}_{\mathrm{t}}\right)$ can be non-zero even when $\omega_{\mathrm{t}}=1$. One cannot, therefore, view earnings as a sufficient statistic when residual earnings follow a random walk as book value still generally enters the valuation function. 


\section{Bibliography}

Barth, Mary E., William H. Beaver, and William R. Landsman, (1998) Relative Valuation Roles of Equity Book Value and Net Income as a Function of Financial Health, Journal of Accounting and Economics 25 (1): 1-34.

Beaver, William H., 1999, Comments on 'An Empirical Assessment of the Residual Income Valuation', Journal of Accounting and Economics, 26 (1999), pp 35-42

Feltham, Gerald A., and James A. Ohlson, 1995, Valuation and Clean Surplus Accounting for Operating and Financial Activities. Contemporary Accounting Research (Spring): 689731.

Feltham, Gerald A., and James A. Ohlson, 1999, Residual Earnings Valuation With Risk and Stochastic Interest Rates, Volume 74, No. 2 - April 1999.

Hand, John, 2001, Discussion of Earnings, Book Values, and Dividends in Equity Valuation: An Empirical Perspective., Contemporary Accounting Research Vol. 18 No. 1, Spring 2001.

Huang, C. and R. H. Litzenberger. Foundations of Financial Economics, North Holland, 1988.Ohlson, James A., 1995, Earnings, Book Values, and Dividends in Equity Valuation, Contemporary Accounting Research Vol. 11 No. 2 (Spring 1995) pp 661-687.

Nissim, Doron, and Stephen Penman, 2000, The Empirical Relationship Between Interest Rates and Accounting Rates of Return, Columbia University Working Paper.

Ohlson, James A., 1995, Earnings, Book Values, and Dividends in Equity Valuation, Contemporary Accounting Research Vol. 11 No. 2 (Spring 1995) pp 661-687.

Ohlson, James A. and Xiao-Jun Zhang, 1998, Accrual Accounting and Equity Valuation Journalof-Accounting-Research;36(0), Supplement 1998, pages 85-111.

Ohlson, James A., 2001, Earnings, Book Values, and Dividends in Equity Valuation: An Empirical Perspective., Contemporary Accounting Research Vol. 18 No. 1, Spring 2001.

Ryan, S., 1988, Structural Models of the Accounting Process and Earnings, Ph.D. Dissertation, Stanford University. 
Yee, Kenton (2001), Ph.D. Thesis, Graduate School of Business, Stanford University.

Zhang, Xiao-Jun, 2000, Conservative Accounting and Equity Valuation, Journal of Accounting and Economics (February 2000): 125-149 